\title{
Perinatal outcomes in twin pregnancies complicated by maternal morbidity: evidence from the WHO Multicountry Survey on Maternal and Newborn Health
}

Danielly S. Santana ${ }^{1}$, Carla Silveira ${ }^{1}$, Maria L. Costa ${ }^{1}$, Renato T. Souza ${ }^{1}$, Fernanda G. Surita', João P. Souza ${ }^{2}$, Syeda Batool Mazhar ${ }^{3}$, Kapila Jayaratne ${ }^{4}$, Zahida Qureshi ${ }^{5}$, Maria H. Sousa ${ }^{6}$, Joshua P. Vogel ${ }^{2}$, José G. Cecatti ${ }^{*}$ (D) and on behalf of the WHO Multi-Country Survey on Maternal and Newborn Health Research Network

\begin{abstract}
Background: Twin pregnancy was associated with significantly higher rates of adverse neonatal and perinatal outcomes, especially for the second twin. In addition, the maternal complications (potentially life-threatening conditions-PLTC, maternal near miss-MNM, and maternal mortality-MM) are directly related to twin pregnancy and independently associated with adverse perinatal outcome. The objective of the preset study is to evaluate perinatal outcomes associated with twin pregnancies, stratified by severe maternal morbidity and order of birth.

Methods: Secondary analysis of the WHO Multicountry Survey on Maternal and Newborn Health (WHOMCS), a cross-sectional study implemented in 29 countries. Data from 8568 twin deliveries were compared with 308,127 singleton deliveries. The occurrence of adverse perinatal outcomes and maternal complications were assessed. Factors independently associated with adverse perinatal outcomes were reported with adjusted PR (Prevalence Ratio) and $95 \% \mathrm{Cl}$.

Results: The occurrence of severe maternal morbidity and maternal death was significantly higher among twin compared to singleton pregnancies in all regions. Twin deliveries were associated with higher rates of preterm delivery (37.1\%), Apgar scores less than 7 at 5th minute (7.8 and 10.1\% respectively for first and second twins), low birth weight (53.2\% for the first and $61.1 \%$ for the second twin), stillbirth (3.6\% for the first and 5.7\% for the second twin), early neonatal death (3.5\% for the first and 5.2\% for the second twin), admission to NICU (23.6\% for the first and 29.3\% for the second twin) and any adverse perinatal outcomes (67\% for the first twin and $72.3 \%$ for the second). Outcomes were consistently worse for the second twin across all outcomes. Poisson multiple regression analysis identified several factors independently associated with an adverse perinatal outcome, including both maternal complications and twin pregnancy.
\end{abstract}

Conclusion: Twin pregnancy is significantly associated with severe maternal morbidity and with worse perinatal outcomes, especially for the second twin.

Keywords: Twin pregnancy, Perinatal outcome, Maternal morbidity

\footnotetext{
*Correspondence: cecatti@unicamp.br

'Department of Obstetrics and Gynecology, University of Campinas,

Alexander Fleming Street, 101, Campinas, SP 13083-891, Brazil

Full list of author information is available at the end of the article
}

(c) The Author(s). 2018 Open Access This article is distributed under the terms of the Creative Commons Attribution 4.0 International License (http://creativecommons.org/licenses/by/4.0/), which permits unrestricted use, distribution, and reproduction in any medium, provided you give appropriate credit to the original author(s) and the source, provide a link to the Creative Commons license, and indicate if changes were made. The Creative Commons Public Domain Dedication waiver (http://creativecommons.org/publicdomain/zero/1.0/) applies to the data made available in this article, unless otherwise stated. 


\section{Background}

Every year more than 10 million infants die before their fifth birthday and 8 million even before their first year of life. Over 6.3 million perinatal death occurred worldwide, in the year 2000, most of them in developing countries [1]. Global efforts and strategies have been aimed at reducing these numbers, including the fourth Millennium Development Goal and the new Sustainable Development Goals, which include ending preventable deaths of newborns and children under 5 years of age in its third goal $[2,3]$. However, it is important to understand the magnitude of perinatal and neonatal morbidity and mortality to address their determinants [1].

Among the obstetric conditions known to increase the risk of perinatal mortality, twin pregnancy is a well-recognized factor [4-6] Twin pregnancy results from a complex interaction of genetic and environmental determinants (maternal age, parity, family history of multiple pregnancies, habits, social conditions) occurring in approximately $2-4 \%$ of livebirths and interestingly, rates are highest in some parts of Africa where care is often poorest [7-10]. However, its incidence increased more than $70 \%$ globally in the last three decades mainly in high and middle-income countries due to the use of assisted reproductive technologies [8, 9, 11, 12]. Twin pregnancy is associated with a number of obstetric complications, some of them with serious perinatal consequences, especially for the second twin $[10,13]$. The rate of perinatal mortality can be up to six times higher in twin compared to singleton pregnancies, largely due to higher rates of preterm delivery and fetal growth restriction seen in twin pregnancies $[4,5,10]$. Preterm birth and birth weight are also significant determinants of morbidity and mortality into infancy and childhood [5].

The risk of maternal mortality is approximately 2.5 times higher in twin than in singleton pregnancies [8]. Maternal death (MD) is understood as the last stage of a continuum of increasingly severe morbidity, which may occur in pregnancy and is preceded by any potentially life-threatening conditions (PLTC) and by maternal near miss (MNM) [14]. Research has been interested in the relationship of twin pregnancies and severe maternal morbidity. A secondary analysis was recently conducted using data from the WHO Global Survey on Maternal and Perinatal Health (2004-2008), where twin pregnancy was a significant, independent risk factor for maternal and perinatal morbidity and mortality compared to singleton pregnancies [6]. A more recent secondary analysis from the WHO Multicountry Survey on Maternal and Newborn Health (WHOMCS, 2010-2011) explored the association of twin pregnancy with adverse maternal outcomes using the MNM criteria, reporting a 3 times higher risk of MNM and a 4 times higher risk of MD among twin pregnancy than in singleton [15]. These analyses, however, did not explore or report on any associations with adverse perinatal outcomes.

The current study aims to asses in the WHOMCS database the prevalence of potentially life-threatening conditions, maternal near miss and maternal death between twin and singleton pregnancies by regions. Then, considering the birth order, to evaluate the prevalence of perinatal outcomes (preterm births, Apgar Score at 5th $\min <7$, fetal death, neonatal death, perinatal death, neonatal intensive care unit admission, adequacy of weight for gestational age) between singleton versus twin. In addition, it aims to identify sociodemographic, obstetric characteristics and the occurrence of maternal complications in singleton and twin deliveries associated with any adverse perinatal outcome.

\section{Methods}

The WHOMCS was a cross-sectional study performed to assess the maternal and perinatal morbidity and mortality in 359 institutions from 29 countries (Afghanistan, Angola, Argentina, Brazil, Cambodia, China, Democratic Republic of the Congo, Ecuador, India, Japan, Jordan, Kenya, Lebanon, Mexico, Mongolia, Nepal, Nicaragua, Niger, Nigeria, Pakistan, Palestine, Paraguay, Peru, Philippines, Qatar, Sri Lanka, Thailand, Uganda, Vietnam), from May 2010 to December 2011. This is a secondary analysis of the database from this worldwide network. Methodological details of the WHOMCS have been previously published elsewhere [16, 17].

Briefly, the survey was conducted in a network of health facilities in Latin America, Africa, Asia and the Middle East, the same that had previously participated in the WHO Global Survey on Maternal and Perinatal Health (2004-2008) [18]. Countries, provinces, and health facilities were randomly selected through a stratified multistage cluster sampling strategy. Countries in each region were selected with a probability proportional to population size. In each country, three sub-regions were also selected: the capital plus two other randomly selected provinces. In each province, seven health facilities with at least 1000 deliveries annually and full capacity for performing caesarean sections were randomly selected. Data was collected from two to four months depending on the annual number of deliveries in each institution. The coordination of the study was of World Health Organization in Geneva; each region had a regional coordinator; each country had a country coordinator; each province had province coordinator, and each facility had a local coordinator who was responsible for selecting some health professional staff to collect data.

Trained data collectors identified eligible subjects in participating facilities. Eligible participants were all women who gave birth during the data collection period in the participating facilities with their respective 
newborns and all women who were admitted with a severe maternal outcome (maternal death or maternal near miss) up to seven postpartum days, independently of gestational age and delivery status. Data were collected from the time of admission to death, discharge or 7 days postpartum/post-abortion (whichever came first), irrespective of gestational age and type of delivery. Adverse outcomes occurring after discharge or during a subsequent readmission were not reported.

A paper form was developed with the following variables, maternal and newborns individual data, data related to pregnancy outcomes, severe complications and their management and characteristics of each health facility. This paper form was reviewed by other researchers and pre-tested on a convenient sample of records and clinical settings; the final version was translated to the main language of each participating country. The medical records were reviewed and the data was completed in the paper form, after that, it was entered into a web-based data management system developed for this purpose; the regional data managers monitored the data flow and the quality of data using data validation and progress reports automatically generated by the system. All instructions regarding eligibility criteria, identification, sociodemographic and obstetric characteristics, maternal complications, neonatal complications, and characteristics of deliveries were standardized in a manual of operations used for training and study operationalization. The training also included workshops at country and facility level and a pilot phase to test the complete data management process.

The study protocol was approved by the WHO Ethical Review Committee and by relevant Institutional Review Boards in participating countries and institutions. The WHOMCS was a study of anonymized data, extracted from medical records (with no contact with women) and therefore individual consent was not required.

At the end of the data collection, 316,695 deliveries were included with complete information on pregnancy outcomes [17]. For this analysis, twin deliveries were compared with singleton deliveries. To define the study groups, 1839 pregnancies with the following conditions were excluded: pregnancies resulting in abortion or ectopic pregnancy; neonate weighing less than $500 \mathrm{~g}$ or with no information on birthweight; less than 22 weeks of gestation; and missing data on termination of pregnancy, final mode of delivery or abortion, and total number of neonates delivered. Analyses were based on 8568 twins and 308,127 singletons (Fig. 1).

\section{Statistical analysis}

The occurrence of maternal outcomes (potentially life-threatening conditions, maternal near miss, maternal death and no complications, according to the WHO

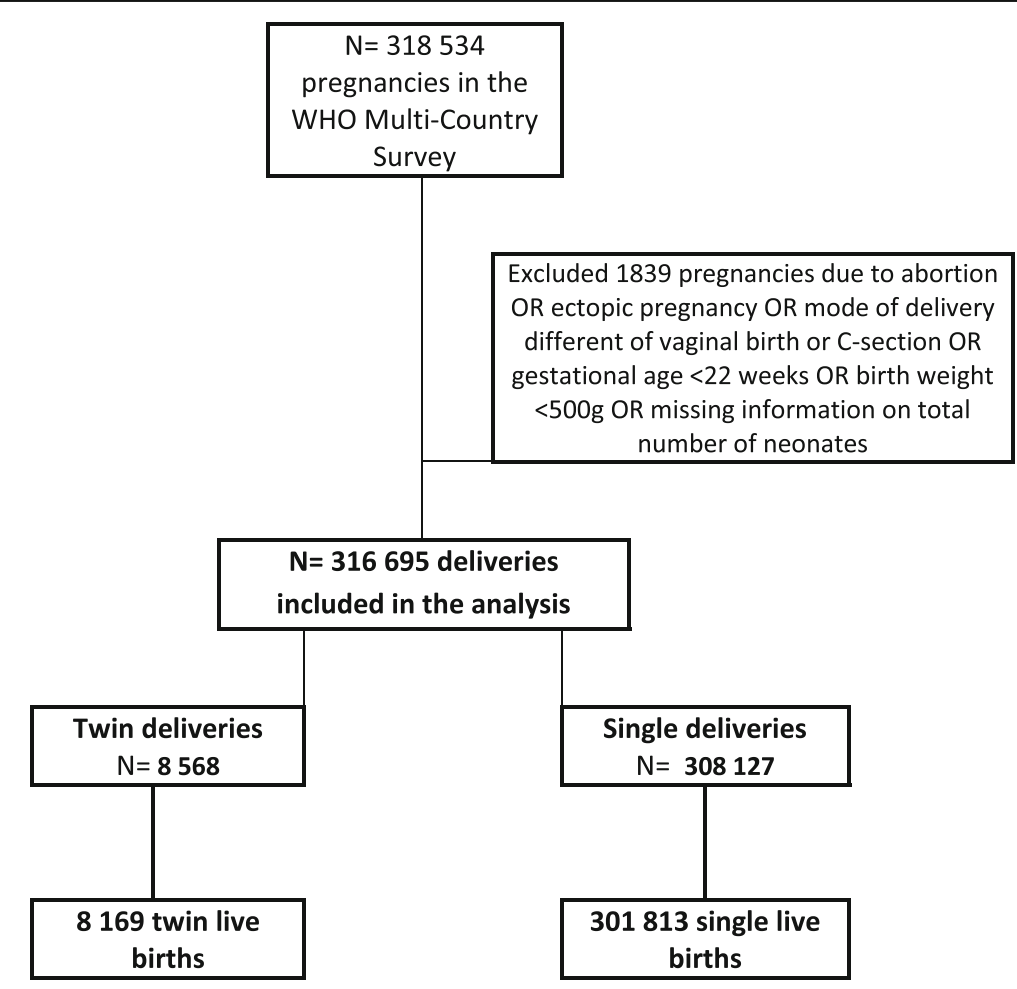

Fig. 1 Flowchart of women in the analysis for adverse perinatal outcomes associated with twin pregnancy (each twin= one delivery) 
definitions and criteria [14]- Fig. 2) was assessed by continent for twin and singleton pregnancies. For this step, women were the unit of analysis. Statistical significance of differences between twins and singletons was assessed by $x^{2}$ tests. The diagnostic criteria used to characterize women with potentially life-threatening conditions, maternal near miss and maternal death are those recommended by WHO (Fig. 2) [14, 17].

For assessing perinatal outcomes, the unit of analysis was neonates (regardless of vital status at birth). Each newborn corresponds to one delivery, so pregnancy resulting in two newborns is considered as two deliveries. We used several perinatal outcomes: Apgar score less than 7 at $5 \mathrm{~min}$, fetal death (the death of a fetus from 22 completed weeks or $500 \mathrm{~g}$ until before birth), early neonatal death (intra-hospital neonatal death in first week of life, occurring prior to discharge), late fetal death (the death of a fetus from 28 weeks until before birth), perinatal death (early neonatal death plus fetal death), preterm birth (birth before 37 weeks gestation), neonatal intensive care unit admission (NICU), and small-for-gestational-age (defined as the weight at childbirth below the 10th percentile for the correspondent gestational age). In addition, we developed two composite outcomes- acute adverse perinatal outcome (AcAPO: Apgar score less than 7 at $5 \mathrm{~min}$, or perinatal death, or neonatal intensive care unit admission) and any adverse perinatal outcome (APO: Apgar score less than 7 at 5 min, or perinatal death, or neonatal intensive care unit admission, or small-for-gestational-age). All perinatal outcomes were separately reported for the first and the second twins, using Prevalence Ratios adjusted by the cluster design effect $\left(\mathrm{PR}_{\mathrm{adj}}\right)$. Comparisons were performed in three steps to assess if they differed by birth order: first twins versus singletons; second twins versus singletons; and second versus first twins. The adequacy of weight for gestational age in the present analysis was evaluated based on Fenton growth chart [19]. The Fenton growth chart is based on the growth target recommended for preterm infants, has specific graphics for girls and boys, and the chart is designed to allow tracing how children are measured, this growth chart was chosen due to the high prevalence of preterm birth in the present study [19].

Differences in sociodemographic, obstetric characteristics and maternal complications (PLTC, MNM, and MD) among twins or singletons according to the occurrence of any adverse perinatal outcome were estimated using $x^{2}$ test.

Finally, a Poisson multiple regression analysis was performed to identify factors independently associated with adverse perinatal outcomes. For that, a regression model was built using acute adverse perinatal outcome and any adverse perinatal outcome as the main outcomes and all

\begin{tabular}{|c|c|c|c|c|}
\hline \multicolumn{5}{|c|}{ PLTC Potentially Life-Threatening Conditions } \\
\hline Hemorrhagic disorders & \multicolumn{2}{|c|}{$\begin{array}{l}\text { Hypertensive } \\
\text { disorders }\end{array}$} & Other systemic disorder & Severe management indicators \\
\hline $\begin{array}{l}\text { Abruptio placentae } \\
\text { Accreta/increta/percreta } \\
\text { placenta } \\
\text { Ectopic pregnancy } \\
\text { Postpartum } \\
\text { haemorrhage } \\
\text { Ruptured uterus }\end{array}$ & \multicolumn{2}{|c|}{$\begin{array}{l}\text { Severe pre-eclampsia } \\
\text { Eclampsia } \\
\text { Severe Hypertension } \\
\text { Hypertensive } \\
\text { encephalopathy } \\
\text { HELLP syndrome }\end{array}$} & $\begin{array}{l}\text { Endometritis } \\
\text { Pulmonary oedema } \\
\text { Respiratory failure } \\
\text { Seizures } \\
\text { Sepsis } \\
\text { Shock } \\
\text { Thrombocytopenia } \\
<100.000 \\
\text { Thyroid crisis }\end{array}$ & $\begin{array}{l}\text { Blood transfusion } \\
\text { Central venous access } \\
\text { Hysterectomy } \\
\text { ICU admission } \\
\text { Prolonged hospital stay ( } 7 \\
\text { days) } \\
\text { Non-anaesthetic intubation } \\
\text { Return to operating room } \\
\text { Surgical intervention }\end{array}$ \\
\hline \multicolumn{5}{|c|}{ MNM Maternal Near Miss } \\
\hline Clinical criteria & & \multicolumn{2}{|c|}{ Laboratory based criteria } & Management based criteria \\
\hline $\begin{array}{l}\text { Acute cyanosis } \\
\text { Gasping } \\
\text { Respiratory rate }>40 \text { or } \\
\text { Shock } \\
\text { Oliguria non-responsive } \\
\text { diuretics } \\
\text { Clotting failure } \\
\text { Loss of consciousness las } \\
\text { Loss of consciousness an } \\
\text { of pulse/heart beat } \\
\text { Stroke } \\
\text { Uncontrollable fit/total p } \\
\text { Jaundice in the presence } \\
\text { eclampsia }\end{array}$ & $\begin{array}{l}\text { /min } \\
\text { fluids or } \\
\text { ing } \geq 12 \mathrm{~h} \\
\text { absence } \\
\text { ralysis } \\
\text { f pre- }\end{array}$ & $\begin{array}{l}\text { Oxygen se } \\
\text { minutes } \\
\mathrm{PaO}_{2} / \mathrm{FiO} \\
\text { Creatinine } \\
3,5 \mathrm{mg} / \mathrm{dl} \\
\mathrm{Bilirubin} \\
\mathrm{mg} / \mathrm{dl} \\
\mathrm{pH}<7,1 \\
\mathrm{Lactate}>5 \\
\text { Acute thrc } \\
\text { platelets) } \\
\text { Loss of co } \\
\text { presence } \\
\text { in urine }\end{array}$ & $\begin{array}{l}\text { mbocytopenia }(<50.000 \\
\text { asciousness and the } \\
\text { flucose and Ketoacids }\end{array}$ & $\begin{array}{l}\text { Use of continuous vasoactive drugs } \\
\text { Hysterectomy following infection or } \\
\text { hemorrhage } \\
\text { Transfusion of } \geq 5 \text { units red cell } \\
\text { transfusion } \\
\text { Intubation and ventilation for } \geq 60 \\
\text { minutes not related to anesthesia } \\
\text { Dialysis for acute renal failure } \\
\text { Cardio-pulmonary resuscitation } \\
\text { (CPR) }\end{array}$ \\
\hline
\end{tabular}

Fig. 2 Definitions of severe maternal complications according to the World Health Organization [14]. Portions reprinted from Say L, Souza JP, Pattinson RC; WHO working group on Maternal Mortality and Morbidity classifications. Maternal near miss — towards a standard tool for monitoring quality of maternal health care. Best Pract Res Clin Obstet Gynaecol 2009; 23:287-96, with permission from Elsevier. HELLP hemolysis, elevated liver enzymes, low platelet count, ICU intensive care unit, CPR cardiopulmonary resuscitation 
other variables as predictors, including the information on the pregnancy being twin or singleton, and the occurrence of maternal complications. The resultant Prevalence Ratios were therefore adjusted not only for the survey design but also for all other predictors $\left(\mathrm{PR}_{\mathrm{adj}}\right)$. Results were considered significant when the estimated $p$-values were below 0.05. All statistical procedures were performed using SPSS (Version 20.0) and Stata (Release 7) programs. Results were reported in accordance with the STROBE statement [20].

\section{Results}

Among the 318,534 women initially enrolled in the WHOMCS, 312,867 women and 316,695 deliveries remained after the exclusion criteria were applied, 4756 (1.5\%) of them with twin pregnancies corresponding to 8568 deliveries of neonates (Fig. 1). Table 1 shows the occurrence of potentially life-threatening conditions, maternal near miss and maternal death by region comparatively between twin and singleton pregnancies. All regions showed significantly higher occurrence of maternal complications and maternal death for twin pregnancies. Rates were consistently higher for the African and Asian regions than for Latin America.

Table 2 shows that twin deliveries were associated with higher rates of preterm birth $(<37$ weeks), early preterm birth $(<34$ weeks), low birth weight, small for gestational age, and Apgar score less than 7. For all perinatal outcomes, rates were significantly higher for twins compared to singletons, and also for the second twin compared to the first twin (Fig. 3).

The occurrence of any adverse perinatal outcome (APO) was more frequent among twin deliveries in women between 18 and 35 years $(87,1 \%)$, with lower maternal education (55,3\% with $0-9$ years of education), higher parity, with a partner, in preterm birth, whose delivery was through an elective C-section. The gestational age at delivery for singleton pregnancies was 37 weeks or more in about $90 \%$ of cases, while in twin pregnancies this prevalence was approximately $65 \%$. In addition, all maternal morbid conditions were more frequent among twins than singletons and more associated with any APO (Table 3).
The factors independently identified as protective for acute or any adverse perinatal outcome were the higher gestational age at birth, vaginal delivery, parity $\geq 1$ and maternal age (Table 4). Any maternal complications (PLTC, MNM and MD) and twin pregnancy were both identified as the main factors associated with a higher risk of APO.

\section{Discussion}

Twin pregnancy has increased risks of preterm labor, spontaneous preterm birth, premature rupture of membranes, neonatal and perinatal morbidity and mortality $[5,10,21,22]$. The occurrence of any potentially life-threatening conditions, maternal near miss or maternal death was twice as high or more, in twin pregnancies; they had complications in $15.3 \%$ while singleton pregnancies had only in $6.8 \%$. Results were reasonably consistent across geographical regions. These outcomes were the object of study in at least another two articles with data from World Health Organization detailing the relationship between twin pregnancy and severe maternal morbidity $[6,15]$. No explanations were found to variable rates of adverse maternal outcomes in twin pregnancies in different countries with similar income, however it may relate to differences in the quality of available care and local complication patterns $[6,15]$.

The reported preterm birth rates among twins are very similar to that found in other studies, ranging from $31 \%$ $[6,22]$ to $44 \%$ [23], but some reporting up to $63 \%$ [24]. Early preterm births are less frequent than late (34-36 weeks), as Vogel et al. reported in the WHO Global Survey, with $11.9 \%$ of preterm birth below 34 completed weeks [6]. Higher early preterm rates are important, as they are associated with higher neonatal morbidity and perinatal death rates, mainly due to respiratory complications $[6,23,25,26]$.

Low birth weight is also more frequent among twin pregnancies. A previous study found that this risk was 8.3 times higher than in singletons, with a mean birth weight of $2300 \mathrm{~g}$ [24], higher than that observed in our study (5 times higher). This risk is associated with the increase in Apgar score at 5th minute $<7$ and death during the first year of life [22-24, 27]. Adequacy of weight

Table 1 PLTC, MNM and MD for twin and singleton pregnancies by region. WHO Multicountry Survey, 2010-2011

\begin{tabular}{|c|c|c|c|c|c|c|c|c|c|}
\hline \multirow[t]{2}{*}{ Region } & \multicolumn{4}{|c|}{ Twin pregnancies } & \multicolumn{4}{|c|}{ Singleton pregnancies } & \multirow{2}{*}{$\begin{array}{l}p \text { - } \\
\text { value }\end{array}$} \\
\hline & NC (\%) & PLTC (\%) & MNM (\%) & MD (\%) & NC (\%) & PLTC (\%) & MNM (\%) & $\mathrm{MD}(\%)$ & \\
\hline Africa & $1219(84 \cdot 2)$ & $196(13.5)$ & $27(1.9)$ & $5(0 \cdot 3)$ & $67,547(93 \cdot 3)$ & $4181(5 \cdot 8)$ & $495(0 \cdot 7)$ & $139(0 \cdot 2)$ & $<0.001$ \\
\hline Asia & $2078(85 \cdot 8)$ & $299(12 \cdot 4)$ & $32(1 \cdot 3)$ & $12(0.5)$ & $161,118(94 \cdot 2)$ & $9129(5 \cdot 3)$ & $686(0.4)$ & $131(0 \cdot 1)$ & $<0.001$ \\
\hline Latin America & $735(82 \cdot 8)$ & $141(15 \cdot 9)$ & $11(1 \cdot 2)$ & $1(0 \cdot 1)$ & $58,412(90 \cdot 3)$ & $5935(9 \cdot 2)$ & $314(0.5)$ & $24(<0 \cdot 1)$ & $<0.001$ \\
\hline TOTAL & $4032(84.8)$ & $636(13.4)$ & $70(1.5)$ & $18(0.4)$ & $287,077(93 \cdot 2)$ & $19,245(6 \cdot 2)$ & $1495(0.5)$ & $294(0 \cdot 1)$ & $<0.001$ \\
\hline
\end{tabular}

MD maternal death, MNM maternal near miss, NC No complication, PLTC potentially life-threatening condition

$P$ value referring to the comparison between no complication/any complication in twin vs singleton 
Table 2 Perinatal outcomes in twin and singleton deliveries (unity of analysis are neonates). WHO Multicountry Survey, 2010-2011

\begin{tabular}{|c|c|c|c|c|c|c|c|}
\hline \multirow[b]{2}{*}{ Gestational age at delivery ${ }^{a}$} & \multicolumn{2}{|c|}{$\begin{array}{l}\text { Twin deliveries } \\
\mathrm{n}(\%)\end{array}$} & \multirow[t]{2}{*}{$\begin{array}{l}\text { Singleton } \\
\text { deliveries } \mathrm{n}(\%)\end{array}$} & \multirow[t]{2}{*}{$\begin{array}{l}\text { Total } \\
\mathrm{n}(\%)\end{array}$} & \multicolumn{3}{|l|}{$\mathrm{PR}_{\mathrm{adj}}(95 \% \mathrm{Cl})$} \\
\hline & & & & & & & \\
\hline$<34$ weeks & \multicolumn{2}{|l|}{$1098(13.0)$} & $7337(2 \cdot 4)$ & $8435(2 \cdot 7)$ & \multicolumn{3}{|l|}{$6.77(5.99-7.66)$} \\
\hline 34-36 weeks & \multicolumn{2}{|l|}{$2035(24 \cdot 1)$} & $14,791(4 \cdot 9)$ & $16,826(5 \cdot 4)$ & \multicolumn{3}{|l|}{$5.57(5.03-6.17)$} \\
\hline$\geq 37$ weeks & \multicolumn{2}{|l|}{$5312(62.9)$} & $282,801(92 \cdot 7)$ & $288,113(91.9)$ & \multicolumn{3}{|l|}{ Ref. } \\
\hline Birth weight ${ }^{b}$ & 1st twin & 2nd twin & & & 1st vs Single & 2nd vs Single & 2nd vs $1 \mathrm{st}$ \\
\hline$<2500 \mathrm{~g}$ & $2495(53 \cdot 2)$ & $2299(61 \cdot 1)$ & $32,480(10 \cdot 6)$ & $37,274(11 \cdot 8)$ & $5.03(4.59-5 \cdot 52)$ & $5.78(5.41-6.17)$ & $1.15(1.06-1 \cdot 24)$ \\
\hline$\geq 2500 \mathrm{~g}$ & $2193(46 \cdot 8)$ & $1464(38.9)$ & $274,665(89 \cdot 4)$ & $278,322(88 \cdot 2)$ & Ref. & Ref. & Ref. \\
\hline \multicolumn{8}{|l|}{ Adequacy of weight for $\mathrm{GA}^{\mathrm{C}}$} \\
\hline SGA & $2385(51.7)$ & $2043(55.2)$ & $77,855(25.7)$ & $82,283(26.4)$ & $2.01(1.88-2.15)$ & $2.15(2.03-2.28)$ & $1.07(1.01-1.13)$ \\
\hline No SGA & $2232(48.3)$ & $1658(44.8)$ & $225,285(74.3)$ & $229,175(73.6)$ & Ref. & Ref. & Ref. \\
\hline \multicolumn{8}{|l|}{ Apgar Score at 5 th $\min ^{d}$} \\
\hline$<7$ & $352(7 \cdot 8)$ & $364(10 \cdot 1)$ & $7928(2 \cdot 6)$ & $8644(2 \cdot 8)$ & $2.97(2.49-3.54)$ & $3.85(3.20-4.63)$ & $1.29(1 \cdot 12-1 \cdot 50)$ \\
\hline $7-10$ & $4142(92 \cdot 2)$ & $3227(89.9)$ & $292,805(97 \cdot 4)$ & $300,174(97 \cdot 2)$ & Ref. & Ref. & Ref. \\
\hline \multicolumn{8}{|l|}{ Fetal and neonatal outcomes } \\
\hline Fetal death ${ }^{\mathrm{e}}$ & $169(3 \cdot 6)$ & $215(5 \cdot 7)$ & $6151(2 \cdot 0)$ & $6535(2 \cdot 1)$ & $1.79(1.52-2.11)$ & $2.83(2.48-3.23)$ & $1.58(1.35-1.86)$ \\
\hline Early neonatal death ${ }^{f}$ & $160(3.5)$ & $189(5 \cdot 2)$ & $2636(0.9)$ & $2985(1.0)$ & $4.03(3.29-4.94)$ & $5.99(4.93-7.29)$ & $1.49(1.26-1.76)$ \\
\hline Late fetal death ${ }^{g}$ & $130(2 \cdot 7)$ & $165(4 \cdot 3)$ & $5241(1.7)$ & $5536(1 \cdot 7)$ & $1.62(1.35-1.94)$ & $2.55(2.21-2.94)$ & $1.58(1.30-1.92)$ \\
\hline Perinatal death ${ }^{\mathrm{h}}$ & $328(7.0)$ & $381(10.0)$ & $8706(2.8)$ & $9415(3.0)$ & $2.46(2.21-2.73)$ & $3.55(3.21-3.90)$ & $1.44(1.14-1.32)$ \\
\hline Preterm births ${ }^{a}$ & $1634(35 \cdot 0)$ & $1492(39.8)$ & $22,128(7 \cdot 3)$ & $25,254(8 \cdot 1)$ & $4.82(4 \cdot 36-5 \cdot 33)$ & $5.48(5.05-5.94)$ & $1.14(1.05-1.23)$ \\
\hline NICU admission ${ }^{i}$ & $1073(23 \cdot 6)$ & $1059(29 \cdot 3)$ & $19,468(6 \cdot 4)$ & $21,600(7 \cdot 0)$ & $3.65(3.23-4.14)$ & $4.54(4.14-4.99)$ & $1 \cdot 24(1 \cdot 12-1 \cdot 38)$ \\
\hline $\begin{array}{l}\text { Acute Adverse } \\
\text { Perinatal Outcome (AcAPO) }{ }^{j}\end{array}$ & 1395 (29.9) & $1390(36.8)$ & $30,006(9.8)$ & $32,791(10.4)$ & $3.06(2.77-3.38)$ & $3.76(3.47-4.08)$ & $1.23(1.11-1.32)$ \\
\hline $\begin{array}{l}\text { Any Adverse Perinatal } \\
\text { Outcome (APO) }{ }^{k}\end{array}$ & $3101(67.0)$ & 2709 (72.3) & $98,128(32.4)$ & $103,938(33.3)$ & $2.07(1.96-2.19)$ & $2.24(2.14-2.34)$ & $1.08(1.03-1.13)$ \\
\hline Total & 4733 & $3811^{1}$ & 308,127 & 316,671 & & & \\
\hline
\end{tabular}

Chi-square test adjusted for the cluster design effect

Missing information for a: 3320; b: 1075; c: 5213; d: 7853; e: 178; f: 6761; g: 159; h: 375; i: 6638; j: 1508; k: 4712 neonates

Values in bold mean they are statistically significant $(p<0.05)$

$A C A P O$ Acute Adverse Perinatal Outcome (Apgar score at 5 th $\min <7$ OR Perinatal death OR NICU admission)

$A P O$ any Adverse Perinatal Outcome (Apgar score at 5 th min $<7$ OR Perinatal death OR NICU admission OR SGA)

'There is no available information for the second or higher twin for the countries Paraguay, Peru, Philippines, Qatar, Thailand, Vietnam and Uganda

for gestational age better assesses the size of the fetus for a given gestational age (compared to birth weight alone). This is particularly useful in populations where preterm birth rates are high. A fetus that is small for gestational age is more likely to experience perinatal morbidity and mortality and adverse effects in adult life [28]. Few studies have evaluated this outcome among twin deliveries, but associations between twin pregnancies and higher rates of small-for-gestational-age have been reported [28, 29]. For these estimations, we used the curves of Fenton et al. [19] because we believed that it was more appropriate to be used when the prevalence of preterm birth is very high, as is the case among twin pregnancies in this population. However, due to the number of cases to have such estimates, it was not feasible to have such assessment performed using different nomograms for comparison.
The risk for low 5th minute Apgar score was three times higher for twin pregnancy (either for the first or second twin) than for singletons. Additionally, it was 1.3 times higher for the second when both twins were compared. This significantly lower Apgar score for the second twin is always taken into consideration in discussions about the best mode of delivery for twin pregnancies and the time interval between first and second twin, although not justifying an indication for a systematic Cesarean section for twin pregnancies [6, 3032]. The higher rates of admission to a neonatal intensive care unit we found have also been reported by previous studies on the topic $[6,31]$.

Prevalence of fetal death of one of the twins varies from $0,5-6,8 \%$ with the worst result for monochorionic pregnancy presenting a high prevalence for this condition $(50-70 \%)$ and risk for the surviving fetus including 


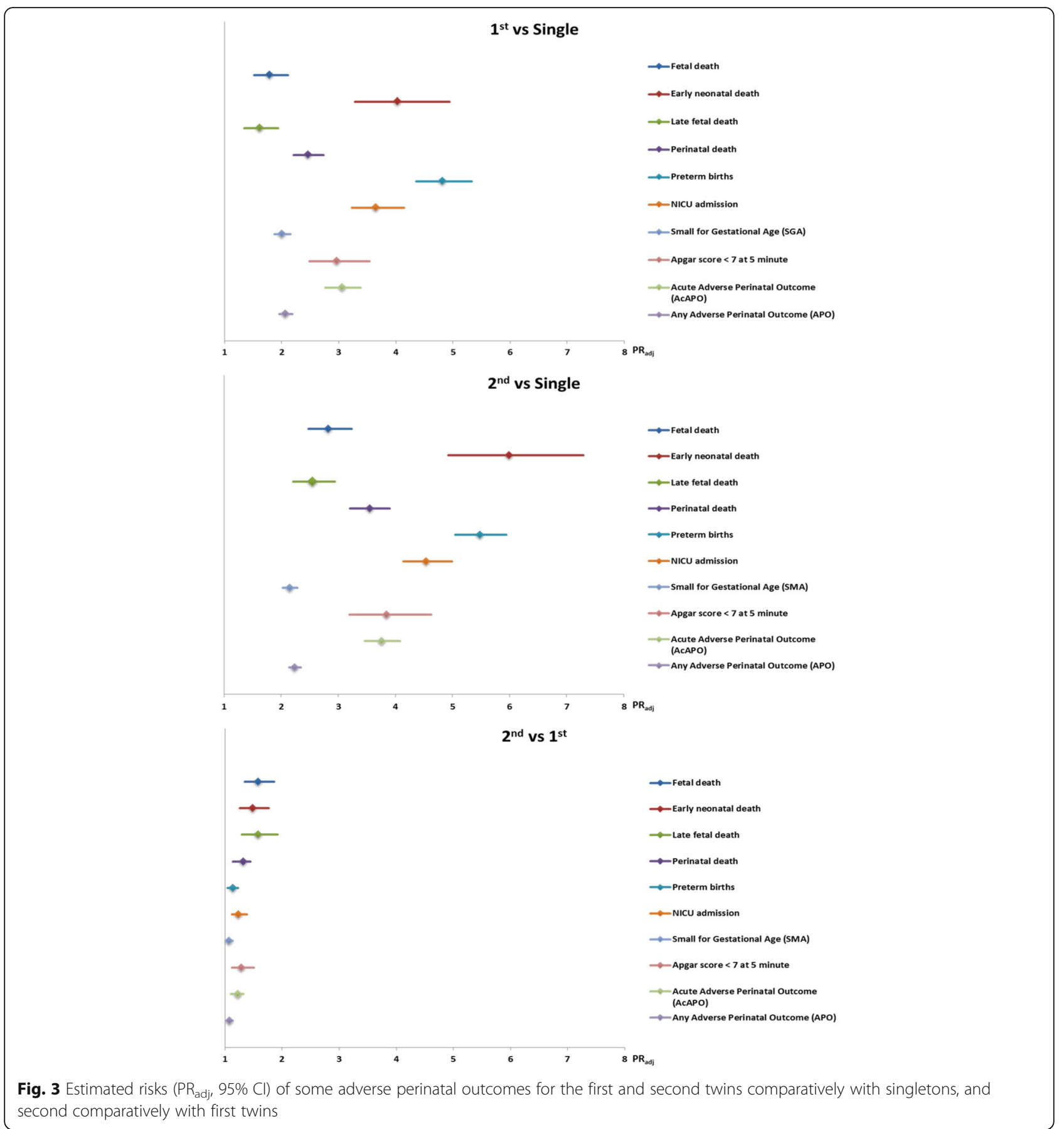

the fetal death of this co-twin, neurological morbidity and iatrogenic preterm delivery $[33,34]$. In the current study, we have not data on chorionicity, however fetal death (death after 28 weeks) occurred over 1.5 times (3.6\%) for the first twin and almost 3 times (5.7\%) for the second twin when compared to singletons (2.0\%).

Perinatal death has been described as up to four times higher in twin pregnancies than in singletons, mainly due to preterm birth, fetal growth restriction, low Apgar scores and extremely low birth weight $[5,6,23,25]$. In our study, it was found to be 2.5 times higher for the first twin and 3.5 for the second one. This difference between both twins has already been described [31]. In the current study, we also observed a higher risk for fetal and early neonatal death, supporting previous findings from other studies $[6,31]$.

Cesarean section, including that performed electively, was the most common mode of delivery in twin 
Table 3 Sociodemographic and obstetric conditions among twin and single deliveries according to the occurrence of any Adverse Perinatal Outcome (APO). WHO Multicountry Survey, 2010-2011

\begin{tabular}{|c|c|c|c|c|c|c|}
\hline \multirow[t]{2}{*}{ Perinatal outcomes } & \multicolumn{2}{|c|}{ Twin deliveries $\mathrm{n}(\%)$} & \multicolumn{2}{|c|}{ Singleton deliveries $\mathrm{n}(\%)$} & \multirow[t]{2}{*}{ Total } & \multirow[t]{2}{*}{$p$-value } \\
\hline & $\mathrm{APO}$ & No APO & $\mathrm{APO}$ & No APO & & \\
\hline \multicolumn{6}{|l|}{ Maternal age $\mathrm{e}^{\mathrm{a}}$} & $<0.001$ \\
\hline$<18$ & $49(1.6)$ & $22(1.4)$ & $3987(4.1)$ & $6971(3.4)$ & 11,029 & \\
\hline $18-35$ & $2693(87.1)$ & $1296(85.0)$ & $86,375(88.3)$ & $179,196(87.6)$ & 269,560 & \\
\hline$>35$ & $349(11.3)$ & $206(13.5)$ & $7510(7.7)$ & $18,420(9.0)$ & 26,485 & \\
\hline \multicolumn{6}{|l|}{ Maternal education (years) ${ }^{b}$} & $<0.001$ \\
\hline $0-4$ & $694(24.6)$ & $259(18.1)$ & $21,295(23.4)$ & $34,647(18.3)$ & 56,895 & \\
\hline $5-9$ & $865(30.7)$ & $414(28.9)$ & $29,664(32.6)$ & $57,190(30.3)$ & 88,133 & \\
\hline$>10$ & $1263(44.8)$ & $758(53.0)$ & $40,025(44.0)$ & $97,219(51.4)$ & 139,265 & \\
\hline \multicolumn{6}{|l|}{ Parity $^{c}$} & $<0.001$ \\
\hline 0 & $1121(36.3)$ & $401(26.3)$ & $47,293(48.3)$ & $81,773(39.9)$ & 130,588 & \\
\hline $1-2$ & $1306(42.3)$ & $793(52.1)$ & $37,017(37.8)$ & $88,631(43.3)$ & 127,747 & \\
\hline$>2$ & $661(21.4)$ & $329(21.6)$ & $13,681(14.0)$ & $34,487(16.8)$ & 49,158 & \\
\hline \multicolumn{6}{|l|}{ Marital status ${ }^{d}$} & 0.013 \\
\hline With no partner & $251(8.2)$ & $91(6.0)$ & $10,898(11.2)$ & $19,766(9.7)$ & 31,006 & \\
\hline With partner & $2825(91.8)$ & $1422(94.0)$ & $86,434(88.8)$ & $183,915(90.3)$ & 274,596 & \\
\hline \multicolumn{6}{|l|}{ Gestational age at delivery ${ }^{\mathrm{e}}$} & $<0.001$ \\
\hline$<34$ weeks & $488(15.8)$ & $74(4.8)$ & $5966(6.1)$ & $1329(0.6)$ & 7857 & \\
\hline 34-36 weeks & $619(20.1)$ & $435(28.5)$ & $5850(6.0)$ & $8838(4.3)$ & 15,742 & \\
\hline$\geq 37$ weeks & $1972(64.0)$ & 1017 (66.6) & $86,010(87.9)$ & 195,007 (95.0) & 284,006 & \\
\hline \multicolumn{6}{|l|}{ Onset of labour ${ }^{f}$} & $<0.001$ \\
\hline Spontaneous & 3902 (67.2) & $1611(62.9)$ & $74,825(76.4)$ & $159,268(77.7)$ & 239,606 & \\
\hline Induced & $455(7.8)$ & $162(6.3)$ & $11,572(11.8)$ & $20,638(10.1)$ & 32,827 & \\
\hline Elective C-section & $1446(24.9)$ & 787 (30.7) & $11,561(11.8)$ & $25,054(12.2)$ & 38,848 & \\
\hline \multicolumn{6}{|l|}{ Mode of delivery ${ }^{g}$} & $<0.001$ \\
\hline Vaginal birth & 1575 (50.8) & $691(45.3)$ & $70,422(71.8)$ & $146,340(71.3)$ & 219,028 & \\
\hline Cesarean section & $1525(49.2)$ & $835(54.7)$ & $27,701(28.2)$ & $58,834(28.7)$ & 88,895 & \\
\hline \multicolumn{6}{|l|}{ Maternal complications ${ }^{\mathrm{h}}$} & $<0.001$ \\
\hline No complications & $2606(84.1)$ & $1312(86.0)$ & $88,416(90.1)$ & $194,250(94.7)$ & 286,584 & \\
\hline PLTC & $425(13.7)$ & $200(13.1)$ & $8567(8.7)$ & $10,365(5.1)$ & 19,557 & \\
\hline MNM & $53(1.7)$ & $13(0.9)$ & $921(0.9)$ & $507(0.2)$ & 1494 & \\
\hline MD & $16(0.5)$ & $1(0.1)$ & $221(0.2)$ & $52(0.0)$ & 290 & \\
\hline \multirow[t]{2}{*}{ Total } & 5810 & 2562 & 98,128 & 205,178 & 311,678 & \\
\hline & 8372 & & 303,306 & & & \\
\hline
\end{tabular}

*design-based $p$-value

Missing information for: a: 9597; b: 32378; c: 9178; d: 11069; e: 9066; f: 5390; g: 8748; and h: 8746 cases

APO any Adverse Perinatal Outcome (Apgar score at 5th min $<7$ OR Perinatal death OR NICU admission OR SGA)

$M D$ maternal death, MNM maternal near miss, PLTC potentially life-threatening condition

pregnancy in the present study. The debate on the best mode of delivery is extensive, especially considering higher adverse outcomes for the second twin, and that neither labor nor vaginal delivery is associated with worse perinatal outcomes, since the first twin is in cephalic presentation. There is currently no indication for a policy of planned cesarean delivery, although still some controversies frequently arise among professionals [11, 12, 30, 35, 36].

In the current analysis higher rates of maternal complications are directly related to twin pregnancy $(15.9 \%$ in twins with APO, $14.1 \%$ in twins with no APO and 9.8\% in singletons with APO and 5.3\% in singletons with no APO). This reinforces some recent studies identifying 
Table 4 Factors independently associated with Acute Adverse Perinatal Outcome (AcAPO) and with any Adverse Perinatal Outcome (APO) by Poisson multiple regression analysis. WHO Multicountry Survey, 2010-2011

\begin{tabular}{|c|c|c|c|}
\hline Model/Variables & $P R_{a d j}$ & $95 \% \mathrm{Cl}$ & $\mathrm{p}$ \\
\hline \multicolumn{4}{|l|}{ AcAPO $[n=283,549]$} \\
\hline Gestational age at delivery (weeks) & 0.81 & $0.80-0.82$ & $<0.001$ \\
\hline Maternal complications (PLTC, MNM, MD) & 1.88 & $1.76-2.02$ & $<0.001$ \\
\hline Group (Twin) & 1.50 & $1.40-1.61$ & $<0.001$ \\
\hline Mode of delivery (Vaginal) & 0.64 & $0.58-0.70$ & $<0.001$ \\
\hline Parity $(\geq 1)$ & 0.86 & $0.81-0.91$ & $<0.001$ \\
\hline Marital status (With no partner) & 1.43 & $1.12-1.83$ & 0.004 \\
\hline Maternal education (Up to nine years) & 1.18 & $1.04-1.33$ & 0.011 \\
\hline Maternal age (years) & 1.006 & $1.001-1.011$ & 0.014 \\
\hline \multicolumn{4}{|l|}{ APO $[n=283,393]$} \\
\hline Group (Twin) & 1.87 & $1.78-1.97$ & $<0.001$ \\
\hline Maternal complications (PLTC, SMM, MD) & 1.39 & $1.32-1.46$ & $<0.001$ \\
\hline Parity $(\geq 1)$ & 0.82 & $0.80-0.85$ & $<0.001$ \\
\hline Gestational age at delivery (weeks) & 0.96 & $0.95-0.97$ & $<0.001$ \\
\hline Maternal education (Up to nine years) & 1.23 & $1.15-1.32$ & $<0.001$ \\
\hline Maternal age (years) & 0.99 & $0.986-0.994$ & $<0.001$ \\
\hline
\end{tabular}

AcAPO Acute Adverse Perinatal Outcome (Apgar score at 5th min $<7$ OR Perinatal death OR NICU admission)

$A P O$ any Adverse Perinatal Outcome (Apgar score at 5 th $\min <7$ OR Perinatal death OR NICU admission OR SGA)

$\mathrm{PR}_{\mathrm{adj}}=$ prevalence ratio adjusted for cluster effect; $95 \% \mathrm{Cl}: 95 \%$ confidence interval for prevalence ratio

Poisson multiple regression analysis, controlled by: Group (Single:0; Twin: 1); Age (years); Maternal education (Up to nine years: 1 ; > 10 years: 0); Parity (0/ $\geq 1: 1$ );

Marital status (With no partner: 1/With partner: 0); Gestational age at delivery (weeks); Onset of labor (Spontaneous: 0; Other: 1); Mode of delivery (Vaginal: 1; C-

section: 0); Maternal complications (No complication: 0/PLTC, MNM, MD: 1)

twin pregnancy as a risk factor for the occurrence of severe maternal morbidity. In a WHO Global Survey analysis, Vogel et al. reported a 1.85 higher risk of occurrence of a severe maternal outcome (maternal death, admission to an intensive care unit, blood transfusion or hysterectomy) between twin pregnancies compared to singletons [6]. Using the new WHO diagnostic criteria for severe maternal conditions, another recent study from our group using the same database identified that twin pregnancies increased twofold the risk of occurrence of PLTC, threefold the risk of MNM and fourfold of occurrence of MD compared with singleton pregnancies [15]. These differences reinforce that twin pregnancy is associated with worse outcomes for both newborns and women. Whether this justifies the need for a more specialized care for women with a twin pregnancy, not only aiming at a good perinatal outcome but also for the maternal outcome, is not completely understood and deserves more specific studies $[5,6,12,15,37]$.

In the multivariate analysis, both twin pregnancy and maternal complications (PLTC, MNM and MD) still appear as factors independently associated with acute or any adverse perinatal outcome. As already argued, a twin pregnancy is associated with a number of perinatal complications either acute or chronic. However, the relationship between adverse perinatal outcomes and severe maternal conditions reinforces that when the woman develops an adverse condition, the fetus suffers direct consequences (growth restriction and stillbirth) or indirectly by the need of interrupting pregnancy before term, with all the consequences of being preterm. In view of these results and knowing that twin pregnancy is not a modified condition but maternal complications are preventable conditions through improvement of the quality of obstetric care theattention to the pregnant woman is able to modify the perinatal outcomes associated with a twin pregnancy.

There were a few limitations to our study. We had no data on the chorionicity and pregnancies archived by ART/FIV for twin pregnancies - what could be associated with perinatal outcomes. In addition, there is no information at all on ethnicity and BMI of the women, what could also be associated with both twin pregnancy and perinatal outcomes. This was a big international multicenter study that for collecting information on all deliveries during a period of time should use a very short questionnaire to facilitate data collection. Considering twin pregnancy was not the main objective of the study, these variables were not included. Despite all quality control procedures some inconsistency could occur unnoticed from data collected from each individual women with a paper form until the feeding of the electronic database, either by the reviewer or by the system. The reported patterns probably relate more to Low- and 
Middle-Income Countries settings as a result of the included countries, and therefore the generalization of results for High-Income countries may be limited. In addition, this WHOMCS was mainly performed in secondary and tertiary facilities functioning as referral hospitals with a probable over-representation of maternal complications and maternal/perinatal deaths and considering that the results are based on the facility, countries with low health-facility coverage will be underrepresented, in those facilities the results will probably be lower mainly to severe maternal morbidity. These data might not be representative of maternal outcomes and coverage of essential interventions in smaller facilities or in the community, with variations among countries. In addition, the data collection included only women and newborns up to seven days postpartum or abortion with that cases progressed to maternal and neonatal complications beyond this period may be lost.

On the other hand, we could also highlight some strengths of the current study. The WHOMCS is a large, multi-country database and based on information collected in a standardized way; outcome data on more than 8000 twins were captured, and results obtained identify worse perinatal outcomes for twins, especially for the second and the association between severe maternal morbidity and twin pregnancy. These findings allow the understanding that twin pregnancy is not only associated with obstetric complications but also maternal death. In the clinical practice, these results could assist in the implementation of protocols for identification of risk conditions and maternal and perinatal care.

\section{Conclusion}

In this analysis, twin pregnancy was associated with significantly higher rates of adverse neonatal and perinatal outcomes. Our results confirm previous observations of increased perinatal mortality and morbidity; outcomes for the second twin were generally poorer than for the first twin. Despite the limitations discussed above, for being a multicenter study, ours finding confirm the necessary identification of higher risk cases and referral to high complexity facilities with capacity for quality prenatal care and intensive care for newborns. Further studies on the topic would be welcome in the future, especially to assess whether specialized obstetric and neonatal care is able to reduce the occurrence of some complications, thus improving maternal and perinatal outcomes.

\section{Abbreviations}

AcAPO: Acute adverse perinatal outcome; APO: Any adverse perinatal outcome; MD: Maternal death; MM: Maternal mortality; MNM: Maternal near miss; NICU: Neonatal intensive care unit; PLTC: Potentially life-threatening conditions; PR: Prevalence Ratio; WHO: World Health Organization

\section{Acknowledgements}

We thank all members of the WHO Multi-Country Survey on Maternal and Newborn Health Research Network, including regional and country coordinators, facility coordinators, data collectors, and all staff of the participating facilities who made the survey possible. This manuscript represents the views of the named authors only, and not the position of their institutions or organizations.

\section{Funding}

Study supported by the UNDP/UNFPA/UNICEF/WHO/World Bank Special Programme of Research, Development and Research Training in Human Reproduction (HRP), World Health Organization (WHO), United States Agency for International Development (USAID), the Ministry of Health, Labour and Welfare of Japan, and Gynuity Health Projects. Specifically for this analysis, a sponsorship from the University of Campinas was provided (Faepex, grant 11014). Funding agencies played no other role nor influenced data analysis, interpretation of results and writing the manuscript.

\section{Availability of data and materials}

The data that support the findings of this study are available from the World Health Organization but restrictions apply to the availability of these data, which were used under license for the current study, and so are not publicly available. Data are however available from the WHO upon reasonable request and with permission of the director of the WHO-RHR (Reproductive Health Research) unit

\section{Author's contributions}

Conceived and designed the experiments: DSS, JGC, FGS, CS, MLC, JPS. Performed the experiments: JGC, CS, MLC, JPS, SBM, KJ, ZQ, JPV. Analyzed the data: DSS, JGC, MHS, RTS. Contributed reagents/materials/analysis tools: DSS, JGC, FGS, CS, MLC, JPS, SBM, KJ, ZQ, JPV, RTS. Wrote the paper: DSS, JGC, FGS, MLC. Final review of manuscript and agreement: all the authors.

\section{Ethics approval and consent to participate}

The study protocol was approved by the WHO Ethical Review Committee and by relevant Institutional Review Boards in participating countries and institutions. The WHOMCS was a study of anonymized data, extracted from medical records (with no contact with women) and therefore individual consent was not required.

Consent for publication

Not applicable.

Competing interests

Prof. Fernanda G Surita is an Associate Editor of BMC Pregnancy and Childbirth. The authors declare that they have no competing interests.

\section{Publisher's Note}

Springer Nature remains neutral with regard to jurisdictional claims in published maps and institutional affiliations.

\section{Author details}

${ }^{1}$ Department of Obstetrics and Gynecology, University of Campinas, Alexander Fleming Street, 101, Campinas, SP 13083-891, Brazil. ²UNDP/ UNFPA/UNICEF/WHO/World Bank Special Programme of Research, Development and Research Training in Human Reproduction (HRP), Department of Reproductive Health and Research, World Health

Organization, Geneva, Switzerland. ${ }^{3}$ Pakistan Institute of Medical Sciences, Islamabad, Pakistan. ${ }^{4}$ Maternal \& Child Morbidity \& Mortality Surveillance Unit, Family Health Bureau, Ministry of Health, Colombo, Sri Lanka. ${ }^{5}$ Department of Obstetrics and Gynecology, University of Nairobi, Nairobi, Kenya.

${ }^{6}$ Department of Public Health, Jundiai Medical School, Jundiai, Brazil.

Received: 16 April 2018 Accepted: 2 November 2018

Published online: 20 November 2018

References

1. World Health Organization. Neonatal and perinatal mortality: country, regional and global estimates. 2006. http://apps.who.int/iris/bitstream/ 10665/43444/1/9241563206_eng.pdf. Access on 2 ${ }^{\text {nd }}$ Apr. 2016. 
2. United Nations. The Millennium Development Goals Report 2015. http://www.un.org/millenniumgoals/2015_MDG_Report/pdf/ MDG\%202015\%20rev\%20(July\%201).pdf. Access on $2^{\text {nd }}$ Apr. 2016.

3. United Nations. Sustain Dev Goals: 17 goals to transform our world. 2015. http://www.un.org/sustainabledevelopment/health. Access on $2^{\text {nd }}$ Apr. 2016.

4. Rao A, Sairam S, Shehata H. Obstetric complications of twin pregnancies. Best Pract Res Clin Obstet Gynaecol. 2004;18(4):557-76.

5. Rizwan N, Abbasi RM, Mughal R. Maternal morbidity and perinatal outcome with twin pregnancy. J Ayub Med Coll Abbottabad. 2010;22(2):105-7.

6. Vogel JP, Torloni MR, Seuc A, Betrán AP, Widmer M, Souza JP, et al. Maternal and perinatal outcomes of twin pregnancy in 23 low- and middle-income countries. PLoS One. 2013;8(8):e70549

7. Smits J, Monden C. Twinning accros the developing world. PLoS One. 2011; 6(9):e25239.

8. National Institute for Health and Clinical Excellence. Multiple prenancy. The management of twin and triplet pregnancies in the antenatal period. NICE clinical Guideline. 2011. http://guidance.nice.org.uk/cg129. Accessed 2 Apr 2016.

9. Bortolus R, Parazzini F, Chatenoud L, Benzi G, Bianchi MM, Marini A. The epidemiology of multiple births. Human Reprod Update. 1999:5(2):179-87.

10. Ananth CV, Chauhan SP. Epidemiology of twinning in developed countries. Semin Perinatol. 2012;36(3):156-61.

11. Young BC, Wylie BJ. Effects of twin gestation on maternal morbidity. Semin Perinatol. 2012;36(3):162-8.

12. Walker MC, Murphy KE, Pan S, Yang Q, Wen SW. Adverse maternal outcomes in multifetal pregnancies. BJOG. 2004:111:1294-6.

13. Smith GCS, Fleming KM, White IR. Birth order of twins and risk of perinatal death related to delivery in England, Northern Ireland, and Wales, 19942003: retrospective cohort study. BMJ. 2007;334(7593):576.

14. Say L, Souza JP, Pattinson RC. WHO working group on maternal mortality and morbidity classifications. Maternal near miss - towards a standard too for monitoring quality of maternal health care. Best Pract Res Clin Obstet Gynaecol. 2009;23(3):287-96.

15. Santana DS, Cecatti JG, Surita FG, Silveira C, Costa ML, Souza JP, et al. Twin pregnancy and severe maternal outcomes. The World Health Organization Multicountry Survey on Maternal and Newborn Health. Obst Gynecol. 2016; 127(4):631-41.

16. Souza JP, Gülmezoglu AM, Carroli G, Lumbiganon P, Qureshi Z. WHOMCS research group. The World Health Organization multicountry survey on maternal and newborn health: study protocol. BMC Health Serv Res. 2011;11:286.

17. Souza JP, Gülmezoglu AM, Vogel J, Carroli G, Lumbiganon P, Qureshi Z, et al. Moving beyond essential interventions for reduction of maternal mortality (the WHO multicountry survey on maternal and newborn health): a cross-sectional study. Lancet. 2013;381(9879):1747-55.

18. Shah A, Faundes A, Machoki M, Bataglia V, Amokrane F, Donner A, et al. Methodological considerations in implementing the WHO global survey for monitoring maternal and perinatal health. Bull World Health Organ. 2008; 86(2):126-31.

19. Fenton TR, Kim JH. A systematic review and meta-analysis to revise the Fenton growth chart for preterm infants. BMC Pediatr. 2013;13:59.

20. Von Elm E, Altman DG, Egger M, Pocock SJ, Gøtzsche PC, Vandenbroucke $J P$, Initiative STROBE. The strengthening the reporting of observationa studies in epidemiology (STROBE) statement: guidelines for reporting observational studies. Lancet. 2007:370(9596):1453-7.

21. Bangal VB, Patel SM, Khairmar DN. Study of maternal and fetal outcomes in twin gestation at tertiary care teaching hospital. Int J Biomed Advance Res. 2012;3(10):758-62.

22. Qazi G. Obstetric and perinatal outcome of multiple pregnancy. J Coll Physicians Surg Pak. 2011;21(3):142-5.

23. Nwankwo TO, Aniebue UU, Ezenkwele E, Nwafor MI. Pregnancy outcome and factors affecting vaginal delivery of twin at University of Nigeria Teaching Hospital, Enugu. Niger J Clin Pract. 2013;16(4):490-5.

24. Assunção RA, Liao AW, Brizot ML, Krebs VL, Zugaib M. Perinatal outcome of twin pregnancies delivered in a teaching hospital. Rev Assoc Med Bras. 2010;56(4):447-51

25. Werder E, Mendola P, Männistö, O'Loughlin J, Laughon SK. Effect of maternal chronic disease on obstetric complications in twin pregnancies in a United States cohort. Fertil Steril 2013; 100(1): 142-149.

26. Tunçalp O, Souza JP, Hindin MJ, Santos CA, Oliveira TH, Vogel JP, et al. On behalf of the WHO multicountry survey on maternal and newborn Health Research network. Education and severe maternal outcomes in developing countries: a multicountry cross-sectional study. BJOG. 2014;121(Suppl. 1):57-65.
27. Fonseca CR, Strufaldi MW, Carvalho LR, Puccini RF. Risk factors for low birth weight in Botucatu city, SP state, Brazil: a study conducted in the public health system from 2004 to 2008. BMC Res Notes. 2012;5:60.

28. Wen SW, Tan H, Yang O, Walker M. Prediction of small for gestational age by logistic regression in twins. Aust N Z J Obstet Gynaecol. 2005;45(5):399-404.

29. Inde Y, Satomi M, Miyake H, Suzuki S. Neonatal small for gestational age status as a favorable factor for the complete vaginal delivery of both fetuses in Japanese dichorionic twins. J Obstet Gynaecol Res. 2011;37(7):843-50.

30. Barrett JF, Hannah ME, Hutton EK, Willan AR, Allen AC, Armson BA, et al. Twin birth study collaborative group. A randomized trial of planned cesarean or vaginal delivery for twin pregnancy. N Engl J Med. 2013;369(14):1295-305.

31. Jacquemyn Y, Martens G, Ruyssinck G, Michiels I, Van Overmeire B. A matched cohort comparison of the outcome of twin versus singleton pregnancies in Flanders, Belgium. Twin Res. 2003;6(1):7-11.

32. Lindroos $L$, Elfvin $A$, Ladfors $L$, Wennerholm $B$. The effect of twin-to-twin delivery time intervals on neonatal outcome for second twins. BMC Pregnancy and Childbirth. 2018;18:36.

33. Southwest Thames Obstetric Research Collaborative. (STORK). Prospective risk of late stillbirth in monochorionic twins: a regional cohort study. Ultrasound Obstet Gynecol. 2012;39:500-4.

34. Fernandes-Vale E, Dias J, Belandina G, Cahilhe A. Single fetal death in monochorionic twin pregnancy: co-twin prgnosis and neonatal outcome. Acta Medica Port. 2017;30(2):148-51.

35. Liu AL, Yung WK, Yeung HN, Lai SF, Lam MT, Lai FK, et al. Factors influencing the mode of delivery and associated pregnancy outcomes for twins: a retrospective cohort study in a public hospital. Hong Kong Med. 2012;18(2):99-107

36. Asztalos EV, Hannah ME, Hutton EK, Willan AR, Allen AC, Armson BA, et al. Twin birth study: 2-year neurodevelopmental follow-up of the randomized trial of planned caesarean or planned vaginal delivery for twin pregnancy. Am J Obstet Gynecol. 2016;214(3):371.e1-371.

37. Dodd JM, Dowswell T, Crowther CA. Specialised antenatal clinics for women with a multiple pregnancy for improving maternal and infant outcomes. Cochrane Database Syst Rev. 2015;11:CD005300.

\section{Ready to submit your research? Choose BMC and benefit from:}

- fast, convenient online submission

- thorough peer review by experienced researchers in your field

- rapid publication on acceptance

- support for research data, including large and complex data types

- gold Open Access which fosters wider collaboration and increased citations

- maximum visibility for your research: over $100 \mathrm{M}$ website views per year

At $\mathrm{BMC}$, research is always in progress.

Learn more biomedcentral.com/submissions 